\title{
Application and Practice of Blended Teaching in Colleges and Universities
}

\author{
Meng Zhao ${ }^{1}$, Zhen Liu ${ }^{1}$, Ruochen Zhao ${ }^{2, *}$, Yinzhen Liu ${ }^{1}$ \\ ${ }^{1}$ College of Energy and Power Engineering, Inner Mongolia University of Technology, Hohhot, Inner Mongolia \\ 010051, China \\ ${ }^{2}$ Engineering Management Department, Inner Mongolia Honder College of Arts and Sciences, Hohhot, Inner \\ Mongolia, 010070, China \\ ${ }^{*}$ Corresponding author. Email: 20201800230@imut.edu.cn
}

\begin{abstract}
In this paper, the problems existing in the online teaching process of blended teaching are discussed. when the effective means to improve the quality of blended teaching are discussed, the method and practice of "results-oriented" online teaching design, the teaching organization form and interactive strategy of "learner-centered", and the formative evaluation and assessment method of "effective learning as the standard" are analyzed. In this way, this study provides some useful references for improving the quality of curriculum teaching in colleges and universities and for educators who pay attention to the reform of curriculum teaching.
\end{abstract}

Keywords: blended teaching, higher education, teaching resources, interactive strategy

\section{INTRODUCTION}

Based on the goal of cultivating undergraduate teaching talents in colleges and universities, in view of the weak parts of the current teaching links, and with the goal of improving students' ability to solve complex engineering problems, this paper analyzes the current traditional teaching mode, the problem that the teaching of specialized courses is difficult to reflect the professional background and characteristics, and probes into the application and practice of blended teaching in colleges and universitie ${ }^{[1-3]}$.At present, educators in colleges and universities across the country are widely involved in teaching reform and construction ${ }^{[4]}$. Taking this as an opportunity, we should set up a perfect teaching reform team, realize the construction of a comprehensive network teaching platform, and further study the blended teaching mode ${ }^{[5]}$.

\section{BLENDED TEACHING DESIGN METHOD AND PRACTICE}

Online teaching resources are the premise of teaching activities, the traditional classroom teaching through the online form of mobile, to give students sufficient learning time. In the blended teaching mode, teachers in the offline classroom can still focus on the key points and difficulties, or the common problems fed back by the students in the online learning process, while some deeper teaching goals can be achieved in the offline classroom. If we move this part of the content completed in the offline class to the online completion, we need to reform the teaching design plan. The setting of teaching objectives in online network teaching should be in line with the network teaching environment (refer to the ABCD method, see figure 1), in which the teaching conditions are selected according to the students' network environment. For some students, because the network is rare and poor, it is difficult to use platforms such as rain class, so it is necessary to assign teaching tasks separately. In the process of teaching practice, each part of the content echoes with each other, and timely adjusts the teaching methods according to the students' feedback, and organizes the teaching model, as shown in figure 1 and figure2, results-oriented online teaching design and practice. 


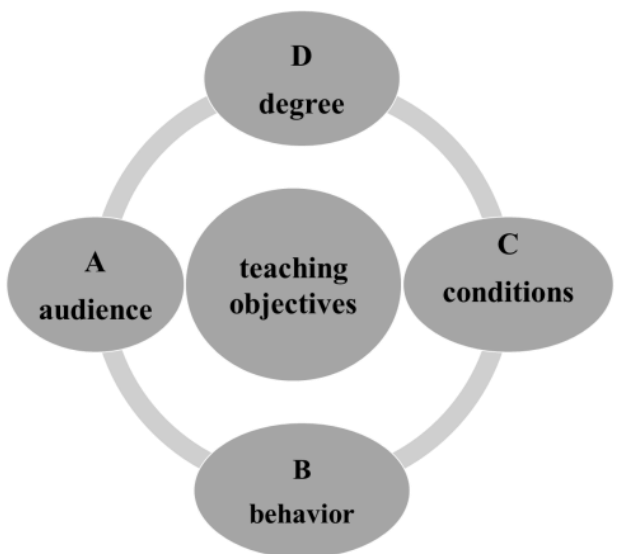

Figure 1 Design of teaching objectives

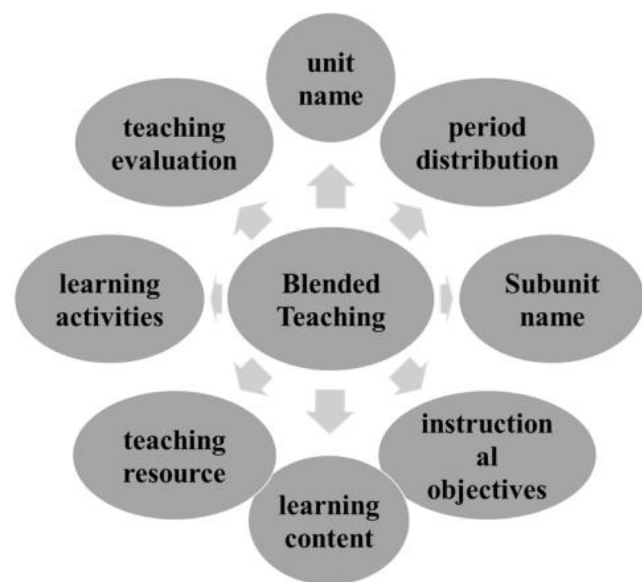

Figure 2 Teaching model design

\section{ORGANIZATION FORM AND INTERACTIVE STRATEGY OF ONLINE TEACHING}

Since the network has been brought into the classroom, it has abandoned the era when there is only blackboard writing, driving students together and combining the educational concept of "student-centered". Therefore, it is necessary to promote students' participation and promote autonomous learning ability. Take the basic courses of engineering majors as an example, in the process of teaching, although we can combine certain life and production examples to arouse students' interest in this course, there are a large number of formula derivation processes in the teaching tasks. Students are more resistant to these tedious processes and lack patience. At the same time, most students are unable to preview this part of the content actively, the classroom time is still limited, and the teaching effect is general.

\subsection{Teaching Organization Form}

Because of the influence of teaching resources, curriculum characteristics and students' ability, it is relatively difficult to integrate the characteristics of different environments in compiling teaching activities.
Therefore, in some difficult concepts, through the form of teaching organization and interactive strategies, e-learning can be effectively integrated. At the same time, relying on the independent online learning stage, it is very important for teachers to carry out real-time monitoring and guidance to students.

Teachers can strengthen communication with students and receive feedback from students through the Internet, and students can show their learning process and achievements through questions, discussions and homework submission. Furthermore, the network teaching documents and corresponding measures should be improved according to the specific conditions of the students. Additionally, in the process of classroom teaching, students' learning of key and difficult contents should be paid attention to and fed back to the web-based teaching documents.

\subsection{Teaching Interaction Strategy}

Blended teaching has a relatively free learning atmosphere, many resources and diverse information, which makes it possible for students to participate based on personality, and have enough time to carry out research and group discussion freely. Due to the different enthusiasm and physical and mental maturity of students, there is a great difference in the ability to 
adapt to the changes of teaching environment and methods in the micro-media era, and there is usually a phenomenon of polarization.

In view of this phenomenon, we should give full play to the guiding function of teachers and improve students' enthusiasm for the curriculum.

Teachers are required to master the process of online teaching as a whole, play the role of macro-control, reasonably use classroom time to explain the key points and difficulties of teaching, and improve the efficiency of online learning through communication and interaction with students, so as to arouse the enthusiasm of the students. In addition, the teacher's enthusiasm and personality charm are also the key to the effectiveness of teacher-student interaction, which contributes to helping students learn to learn and learn to think. In order to pay attention to the mastery of different students, especially those who have difficulties in learning fluid mechanics due to poor mathematical foundation, tests and questionnaires can be adopted, which is helpful to improve teaching organization and interactive strategies in time.

\section{FORMATIVE EVALUATION AND ASSESSMENT METHODS}

The blended teaching obtains the final formative evaluation by the combination of process evaluation and summative evaluation. In the process of teaching reform, the network teaching mode is diversified, and it is necessary to carry out a more comprehensive evaluation index of "effective learning". Relying on the independent online learning stage, through micro-media to achieve a variety of evaluation methods to adapt to different students, as shown in figure 3 .

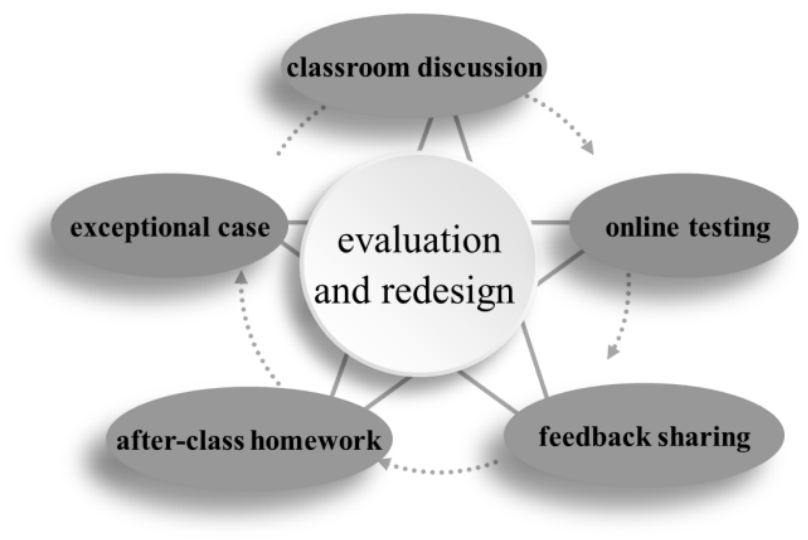

Figure 3 Teaching evaluation and teaching redesign

In the online teaching activities, various factors need to be comprehensively considered in the evaluation of teaching achievements and the redesign of the teaching process by means of after-class homework, online testing, classroom discussion, feedback sharing, etc. A small number of students cannot use the computer side for online learning, most of the online teaching platform mobile end and computer side are different, cannot use a unified standard. Therefore, different evaluation indicators should be formulated after statistics, but the consistency of evaluation contents should be guaranteed, so that the assessment criteria and evaluation indicators echo each other.

\section{CONCLUSION}

In order to reform the traditional teaching mode in colleges and universities and complete the digitization and networking of teaching resources, the traditional classroom should be transformed into a blended classroom, and the interaction between teachers and students and the communication between students should be strengthened, this will effectively improve the dissemination of classroom knowledge and the quality of students' learning, and achieve results-oriented, learner-centered, effective learning as the standard of teaching reform. Moreover, in order to improve the teaching quality of the course and cultivate the students' ability of self-study, innovation and comprehensive analysis and solving practical problems based on the online network platform, this paper explores and studies the key problems and main contents of blended teaching, especially the reform and design of online network teaching mode.

\section{AUTHORS’ CONTRIBUTIONS}

Zhen Liu contributed to the conception of the study;Meng Zhao contributed significantly to analysis and manuscript preparation; Ruochen Zhao and Yinzhen Liu helped perform the analysis with constructive discussions.

\section{ACKNOWLEDGMENTS}

The authors wish to acknowledge the support and motivation provided by the construction project of blended teaching demonstration course: Fluid 
Mechanics A(BC2019007). The authors would like to thank Inner Mongolia University of Technology for helpful discussions on topics related to this work.

\section{REFERENCES}

[1] Liu H, Li Z.G. Research on t-he Application of Blended Learning Mod-el Based on Online Teaching Platform inColleges and Universities. In: National E-ducation and Teaching Innovation and De-velopment High-end Forum. BJ. 2020 pp. 347-348.

[2] Zhao, H.Y. Discussion on Mixed Teaching Model Based on Online and Offline Combination in 2020. In: Basic Education Development Research Summit Forum in 2020. BJ. 2020 pp. 2590-2592.

[3] Zhao, X.M. Discussion on the Transformation of University Education under the Network Environment. In: Seminar on "Research on Integration of Regional Quality Education Resources" in 2020. BJ. 2020. pp. 707-709.

[4] Deng P, Liu J, Zhang J, Xu, P.J. Research on Online and Offline Mixed Teaching Practice. In: The 5th Seminar on Digital Teaching in Primary and Secondary Schools. BJ. 2020 pp. 188-191.

[5] Kang, E.S., Zhao, Y.J., Wang, W.C., Zhao, Z.H., Yang D. Exploration and Practice of Innovative Mixed Teaching Model in Universities. In: The 30th National Conference on Safety Science and Engineering in Universities and the 12th National Seminar on Professional Degree Postgraduate Education in the Field of Safety Engineering. Hefei. pp. 26. 